\title{
Diversidade de Piperaceae em um remanescente de Floresta Atlântica na região serrana do Espírito Santo, Brasil
}

\author{
Valderes Bento Sarnaglia Junior ${ }^{1}$ * \\ Glória Maria Martins Bermudez ${ }^{2}$ \\ Elsie Franklin Guimarães ${ }^{1}$ \\ ${ }^{1}$ Instituto de Pesquisas Jardim Botânico do Rio de Janeiro \\ Rua Pacheco Leão, 915, Jardim Botânico, CEP 22460-030, Rio de Janeiro $\square$ RJ, Brasil \\ ${ }^{2}$ Universidade Federal do Espírito Santo, Departamento de Ciências Biológicas \\ Avenida Fernando Ferrari, 514, Goiabeiras, CEP 29075-910, Vitória $\square$ ES, Brasil \\ * Autor para correspondência \\ valderesbento@yahoo.com.br
}

Submetido em $01 / 03 / 2013$

Aceito para publicação em 25/11/2013

\section{Resumo}

Piperaceae possui 450 espécies no Brasil, ocorrendo em todo o país e com maior riqueza de espécies na Floresta Atlântica e Amazônia. Existe uma carência de pesquisas sobre Piperaceae do estado do Espírito Santo, de modo que este estudo apresenta um tratamento florístico para a família em um fragmento de floresta ombrófila densa em Limoeiro de Santo Antonio $\left(19^{\circ} 56 \square 40 \llbracket \mathrm{S} \mathrm{e} 40^{\circ} 49\lceil 50 \square)\right.$, municipalidade de Itarana-ES. Dez espécies estão representadas na localidade, agrupadas nos gêneros Peperomia Ruiz \& Pav. (uma espécie) e Piper L. (nove espécies), para as quais foi confeccionada uma chave de identificação; elas são descritas, comentadas e ilustradas por meio de fotografias.

Palavras-chave: Flora do Espírito Santo; Peperomia; Piper

\section{Abstract}

Diversity of Piperaceae at an Atlantic Forest remnant in the mountainous region of Espírito Santo, Brazil. Piperaceae has 450 species in Brazil, which occur throughout the country and with higher species richness in the Atlantic Forest and the Amazon Rainforest. There is a lack of researches on Piperaceae from the state of Espírito Santo, so that this study presents a floristic approach to the family at a remnant of dense ombrophilous forest in Limoeiro de Santo Antonio (1956'40"S and 4049'50”W), in the town of Itarana, Espírito Santo, Brazil. Ten species are represented at the site, grouped into the genera Peperomia Ruiz \& Pav. (1 species) and Piper L. (9 species), for which we designed an identification key; they are described, commented, and illustrated by means of photographs.

Key words: Flora from Espírito Santo; Peperomia; Piper 


\section{Introdução}

A família Piperaceae possui ampla distribuição em regiões tropicais e subtropicais, com cerca de 3700 espécies (JARAMILLO et al., 2004; WANKE et al., 2006), das quais 450 ocorrem no Brasil e 98 estão listadas para o Espírito Santo (GUIMARÃES et al., 2012). Piperaceae possui espécies arbustivas eretas ou escandentes, ervas terrestres, rupícolas ou epífitas; possuem ramos com nós proeminentes e folhas pecioladas ou subsésseis; as inflorescências são em espigas ou racemos, solitárias ou dispostas em panículas ou umbelas de espigas; as flores diminutas são aperiantadas, protegidas por brácteas florais de diferentes formas, peltadas ou não, 1-10 estames, 1-5 estigmas e frutos pequenos do tipo drupa (YUNCKER, 1972).

Três gêneros são reconhecidos para a família no Brasil: Manekia Trel., Peperomia Ruiz \& Pav. e Piper L., sendo os dois últimos gêneros os de maior riqueza de espécies para a família e entre os maiores das angiospermas (FRODIN, 2004). Possuem importância econômica, sendo Piper nigrum L., a pimenta-do-reino, a espécie mais conhecida da família; também outras como Piper krukoffii Yuncker, Piper divaricatum G. Mey., Peperomia elongata Kunth e Peperomia blanda (Jacq.) Kunth possuem importância medicinal, sendo utilizadas na produção de óleos essenciais e extratos com potencial antifúngico, antioxidante e larvicida (CAMPOS et al., 2007; FELIPPE et al., 2008; SILVA et al., 2010; 2011). As espécies de Piper ocorrem em diferentes habitats, tanto em clareiras e áreas perturbadas, quanto no sub-bosque, principalmente em florestas úmidas de terras baixas (TEBBS, 1989); servem como fonte de alimentos e são dispersos por morcegos, principalmente do gênero Carollus (FLEMING, 2004). Os táxons de Peperomia ocorrem preferencialmente em locais úmidos e sombreados, habitam preferencialmente florestas ombrófilas e o epifítismo é predominante, porém muitas espécies são encontradas em fendas de rochas ou mesmo no solo (CARVALHO-SILVA, 2008).

O único trabalho taxonômico de flora de Piperaceae com material proveniente do Espírito Santo foi o realizado por Yuncker $(1972 ; 1973 ; 1974)$ para a flora do Brasil que trabalhou com escasso material, oriundo de poucas localidades. De modo que não existem tratamentos taxonômicos específicos para a flora do Estado.

Este trabalho objetiva apresentar o estudo florísticotaxonômico das espécies dessa família ocorrentes em um fragmento de Floresta Atlântica na região serrana do Espírito Santo, a fim de contribuir para o preenchimento de lacunas do conhecimento da flora de Piperaceae para o Estado.

\section{Material e Métodos}

Foi realizado um inventário florístico da família Piperaceae em um fragmento de Floresta Atlântica na localidade de Limoeiro de Santo Antônio (1956 $40 \llbracket \mathrm{S}$ e $40^{\circ} 49 \square 0 \square$ ), no distrito de mesmo nome, município de Itarana, região serrana do Espírito Santo (Figura 1). O fragmento é constituído por reserva legal e área de preservação permanente (APP) de cursos d'água e de encosta, sendo limitado por pastagens e lavouras de cultivo de café. A área de estudo possui aproximadamente 10 ha de floresta em regeneração secundária, às margens do Rio Limoeiro. Trata-se de local em transição de Floresta Ombrófila Densa submontana para montana (senso IBGE, 2012), devido a elevação que varia de 450$550 \mathrm{~m}$. São terras de temperaturas amenas, acidentadas e com período chuvoso de outubro a abril, e temperaturas médias mensais variando de 9,4 a $30,7^{\circ} \mathrm{C}$ (INCAPER, 2013).

A partir de caminhadas nas trilhas existentes às margens do rio foram realizadas coletas aleatórias, sendo que o material coletado foi herborizado segundo a metodologia de Fidalgo e Bononi (1989). As coletas ocorreram entre 2009 e 2012 e o material foi tombado nos Herbários VIES e RB. Para auxiliar a identificação dos espécimes os acervos dos herbários CVRD, MBML, $\mathrm{RB}, \mathrm{SP}$ e VIES foram consultados, porém coleções para a área de estudo são escassas. Para as descrições das formas e padrões de nervação das folhas foi utilizado Hickey (1973) e a descrição dos tipos de tricomas seguiu Hickey e King (2003). São apresentadas chaves de reconhecimento das espécies, bem como, descrições e fotografias ilustrando os principais caracteres. 
FIGURA 1: Localização geográfica do Espírito Santo com detalhe da localização da área de estudo em Limoeiro de Santo Antônio, município de Itarana, sobre um mapa temático de relevo.

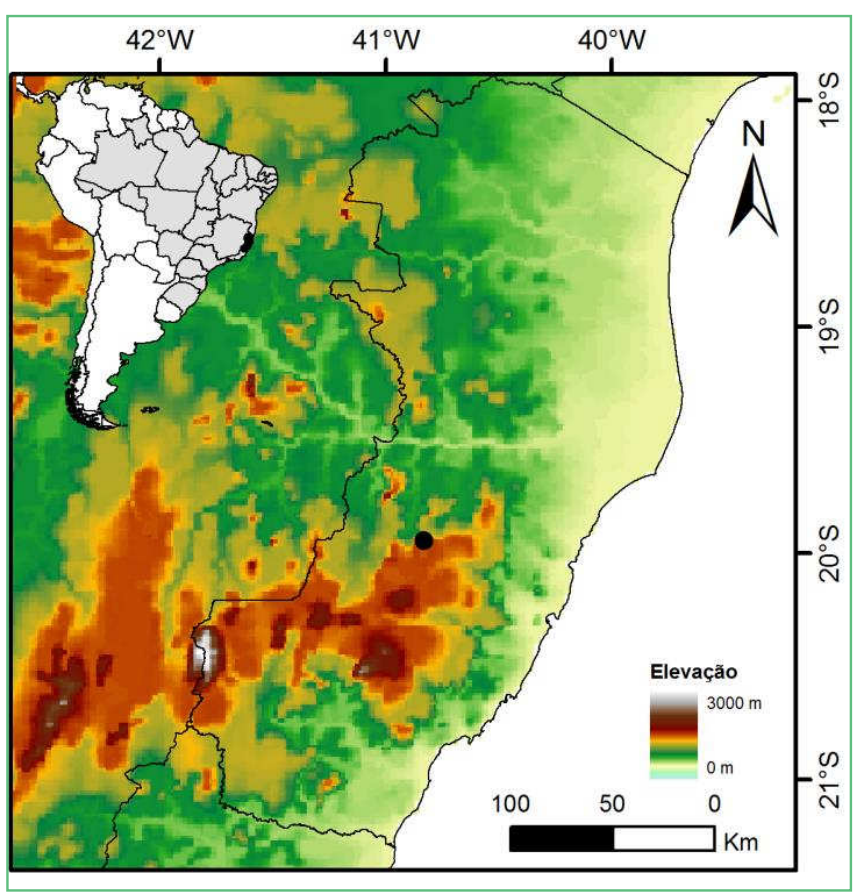

\section{Resultados e Discussão}

Dez espécies representam a família Piperaceae para a localidade, distribuídas nos gêneros Peperomia e Piper. No que se refere à distribuição geográfica: Piper aduncum L., P. amalago L. P. arboreum Aubl., $P$. tuberculatum Jacq. e $P$. umbellatum L. apresentam distribuição pan-americana (YUNCKER, 1972; 1973); P. anonifolium Kunth e $P$. crassinervium Kunth ocorrem da Floresta Atlântica até a Amazônia na América do Sul; enquanto $P$. caldense C. DC.e P. mollicomum Kunth são endêmicas do Brasil e presentes na Floresta Atlântica, Cerrado e Amazônia (GUIMARÃES et al., 2012). Peperomia pereirae f. hirtulicaule Yunck. foi apontada por Yuncker (1966; 1974) para o Estado do Espírito Santo com apenas o material tipo, de modo que com as novas coletas realizadas, sua descrição é agora complementada após 64 anos depois da coleta do tipo.

\section{Chave de identificação para os táxons de Piperaceae para a área de estudo}

1. Ervas rupícolas ou epífitas, 1 estigma.

Peperomia pereirae f. hirtulicaule

1. Arbustos ou subarbustos, 3-4 estigmas

2. Espigas reunidas em umbelas

Piper umbellatum

2. Espigas solitárias

3. Folhas com padrão de nervação acródromo

Piper amalago

3. Folhas com padrão de nervação broquidódromo ou eucamptódromo

4. Lâmina foliar comnervuras secundárias ultrapassando o terço superior da folha

5. Pecíolos glabros

6. Lâmina foliar não glandulosa com base assimétrica diferindo um lado do outro em 9-20 mm, espigas eretas. Piper arboreum var. arboreum

6. Lâmina foliar profuso glandulosa com base assimétrica diferindo um lado do outro 2-3 $\mathrm{mm}$, espigas pêndulas

Piper caldense

5. Pecíolos puberulentos ou com duas linhas de tricomas

7. Nós providos de tubérculos, pecíolo puberulento, espigas $5-10 \mathrm{~cm}$ compr., bráctea floral triangular.........

Piper tuberculatum

7. Nós desprovidos de tubérculos, pecíolo com duas linhas de tricomas, espigas 1-2,2 cm compr., bráctea floral cuculada. Piper anonifolium

4. Lâmina foliar com nervuras secundárias não ultrapassando o terço superior da folha

8. Estilete longo. Piper crassinervium

8. Estilete ausente

9. Face abaxial da lâmina foliar com tricomas foliares sedosos ao toque Piper mollicomum

9. Face abaxial da lâmina foliar com tricomas foliares ásperos ao toque. Piper aduncum 
Peperomia pereirae f. hirtulicaule Yunck. Bol. Inst. Bot. (São Paulo) 3: 164-165. 1966.

Figura $2 \mathrm{a}-\mathrm{b}$

Erva ca. $20 \mathrm{~cm}$ alt., epífita ou rupícola, suculenta, estolonífera, assurgente, esparsamente hirtela. Folhas 3-verticiladas, pecíolo 2-5 mm compr.; lâmina 5,7-9,7 x 2,2-3,9 cm, elíptica, estreito-elíptica, oblanceolada, coriácea com glândulas negras, base acuminada, ápice agudo, 3-5 nervuras, acródroma basal. Espigas 1-3, terminais ou axilares, eretas, $12-20 \times 0,1 \mathrm{~cm}$, pedúnculo 1,8-3,5 cm, hirtelo; bráctea floral orbicular, peltada,

FIGURA 2: Peperomia pereirae f. hirtulicaule (Sarnaglia Jr. 157): a. Hábito, b. Fruto, evidenciando a pseudocúpula; Piper aduncum (Sarnaglia Jr. 59): c. Pedúnculo, d. Folha; P. amalago: e. hábito (Sarnaglia Jr. 68), f. Fruto com ápice agudo (Kolmann \& Krause 9023); P. anonifolium (Sarnaglia Jr. 529): g. Espiga, h. Base do pecíolo com setas vermelhas indicando as duas linhas de tricomas; P. mollicomum: i. Hábito; P. arboreum (Sarnaglia Jr. 358): j. Folha; P. caldense (Sarnaglia Jr. 357): k. Folha, 1. Espiga pendente; P. crassinervium: m. Folha (Sarnaglia Jr. 360), n. Detalhe da espiga evidenciando o ovário com estilete longo e estigmas curvados (Pereira 5373); P. tuberculatum (Sarnaglia Jr. 465): o. Nós providos de tubérculos, p. Frutos e brácteas florais triangulares; P. umbellatum (Sarnaglia Jr. 187): q. Espigas reunidas em uma umbela axilar.
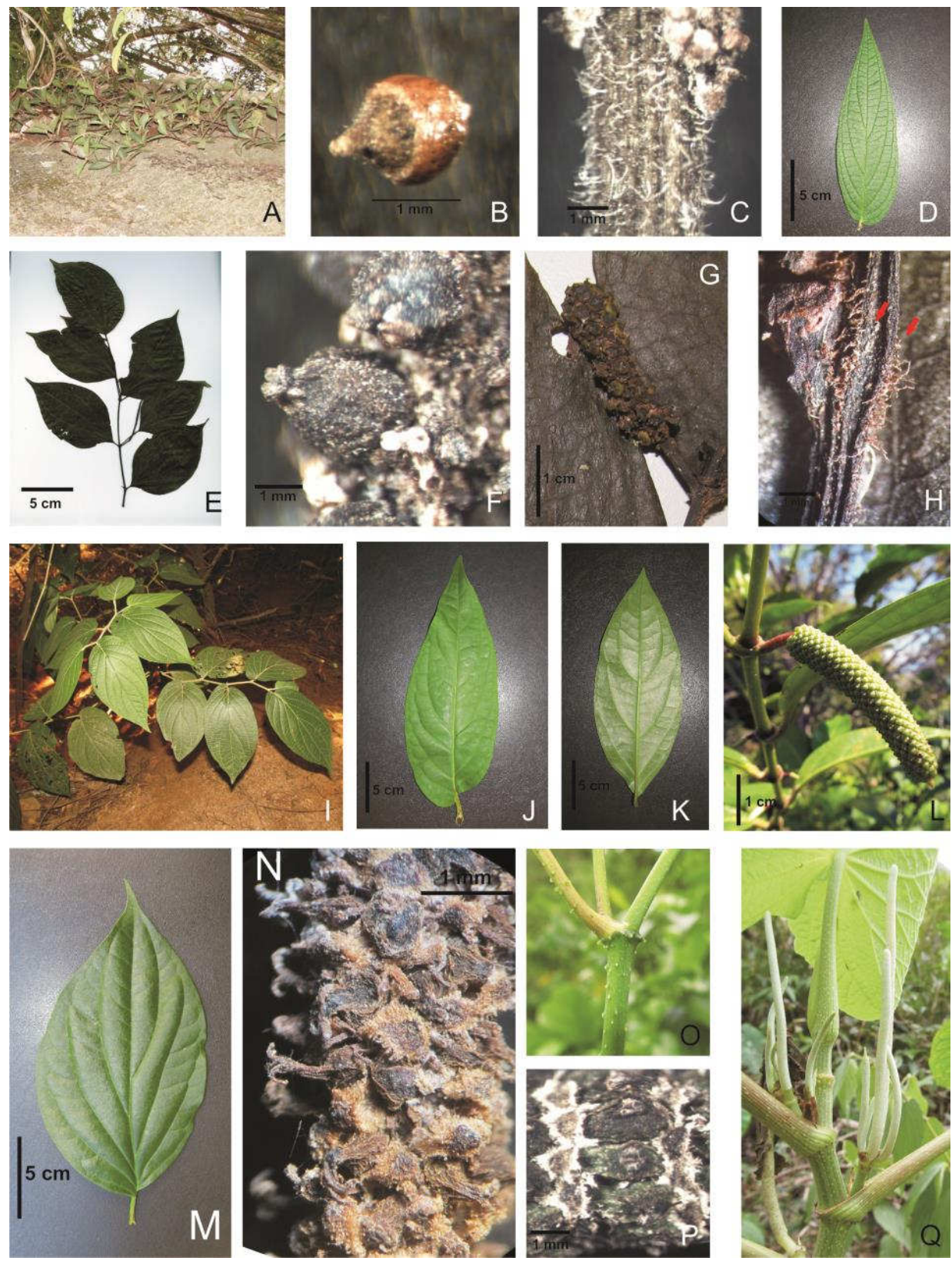
glabra; estames 2, estigma 1, apical. Fruto ca. $1 \mathrm{~mm}$, glabro, glanduloso, ovoide, com pseudocúpula, ápice agudo.

Material examinado: Brasil, ES, Itarana, Limoeiro de Santo Antônio, 05.IX.2009 (fr.), V.B. Sarnaglia Junior 157 (VIES); 09.VIII.2010 (fl.), V.B. Sarnaglia Junior 359 (VIES); 01.IX.2012 (fr.), V.B. Sarnaglia Junior 463 (VIES).

Material adicional: BRASIL, ES, Itaguassú [Itarana], Jatiboca, 31.V.1946. (fl.), Brade et al. 18508 (RB Holótipo).

Comentários: Peperomia pereirae f. hirtulicaule é facilmente encontrada como rupícola, ciófila, em matacões próximos a corpos dágua. O hábito de erva, os ramos e pecíolos vináceos, além das folhas verticiladas, tornam fácil o reconhecimento da espécie em campo, quando comparadas as outras espécies da mesma localidade.

Piper aduncum L., Sp. Pl. 29. 1753.

Figura $2 \mathrm{c}-\mathrm{d}$

Arbusto 1-2 m alt., ramos com tricomas pubérulos. Folhas alternas, pecíolo 1-3 cm compr., vaginado na base, pubérulo; lâmina 12,5-25,7 x 2,6-7,9 cm, elíptica, estreito-elíptica, lanceolada, cartácea, castanhoglandulosa, escabra na face adaxial, pubérula na abaxial, base assimétrica diferindo um lado do outro em 2-4 mm compr., obtusa a levemente cordada, raro aguda, ápice agudo a acuminado, eucamptódroma, com 4-6 pares de nervuras secundárias, dispostos até um pouco acima da porção mediana da lâmina. Espigas opostas às folhas, solitárias, arqueadas, apiculada, 5,4-13 x 0,2-0,3 cm; pedúnculo 0,7-1,4 cm compr., pubérulo; bráctea floral triangular, subpeltada, glandulosa acima e densamente fimbriada lateralmente; estames 4, estigmas 3, filiforme, estilete ausente. Fruto ca. $1 \mathrm{~mm}$ compr., glabro, glanduloso, obovoide, tetragonal, ápice depresso.

Material examinado: Brasil, ES, Itarana, Limoeiro de Santo Antônio, 23.VII.2009 (fl.fr.), V.B. Sarnaglia Junior 59 (VIES); 09.VIII.2010 (fr.), V.B. Sarnaglia Junior 354 (VIES); 07.IX.2010 (fl.fr.), V.B. Sarnaglia Junior 361 (VIES); 01.IX.2012 (fr.), V.B. Sarnaglia Junior 464 (RB).
Comentários: Arbusto heliófilo encontrado próximo a estradas ou clareiras. Reconhecida em campo pelas folhas pendentes com a superfície adaxial escabra, áspera ao toque e espigas arqueadas.

\section{Piper amalago L., Sp. Pl. 29. 1753.}

Figura 2 e-f

Arbusto 1-2,5 m alt., ramos pubescentes. Folhas alternas, pecíolo 4-7 $\mathrm{mm}$ compr., vaginado na base, pubescente; lâmina 7,5-12,2 x 4-7,1 cm, largo-elíptica, elíptica, base simétrica, aguda a obtusa, ápice acuminado, cartácea, pubescente a puberulenta nas nervuras principais, acródroma basal, com 5 nervuras principais. Espigas opostas às folhas, solitárias, semieretas, 3,5-9,5 x 0,2-0,3 $\mathrm{cm}$; pedúnculo 0,5-1,2 cm compr., puberulento; bráctea floral suborbicular, subpeltada, fracamente fimbriada lateralmente, papilosa acima; estames 6, estigmas 4 , espessos, estilete ausente. Fruto ca. $3 \mathrm{~mm}$ compr., glabro, ovoide, ápice agudo.

Material examinado: Brasil, ES, Itarana, Limoeiro de Santo Antônio, 20.IV.2009 (fl.), V.B. Sarnaglia Junior 68 (VIES).

Material adicional: Brasil, ES, Santa Teresa, 11.V.2006 (fr.). L. Kolmann \& S. Krause 9023 (MBML).

Comentários: Arbusto que se desenvolve próximo corpos d'água, em áreas sombreadas ou abertas; suas folhas brilhantes apresentam padrão de nervação acródromo e as espigas, quando em frutos, os tem com ápice agudo.

\section{Piper anonifolium Kunth, Linnaea 13: 619. 1839[1840].}

Figura $2 \mathrm{~g}-\mathrm{h}$

Subarbusto com até $1 \mathrm{~m}$ alt., ramos glabros. Folhas alternas, pecíolo 0,5-2,2 cm compr., vaginado, canaliculado, glabro, exceto pelas duas linhas de tricomas na base do pecíolo decurrentes no caule; lâmina 9-14,3 x 2,8-5,2 cm, oblonga, estreito-oblonga, elíptica, levemente discolor, cartácea, glabra, base simétrica, obtusa a arredondada, ápice agudo, broquidódroma, com 8-11 pares de nervuras secundárias, dispostos ao longo da lâmina. Espigas opostas às folhas, solitárias, eretas, 1,5-2,2 x 0,5-0,6 cm; pedúnculo 0,5-0,9 cm compr., 
glabro; bráctea floral cuculada, glabra; estames 5-6, estigmas 3, filiformes, estilete ausente. Fruto 2-3 mm compr., glanduloso, obovoide, ápice depresso.

Material examinado: Brasil, ES, Itarana, Limoeiro de Santo Antônio, 23.VII.2009 (fl.fr.), V.B. Sarnaglia Junior 67 (VIES); 28.IX. 2012 (fr.), V.B. Sarnaglia Junior 529 (RB).

Material adicional: Brasil, ES, Itarana, Jatibocas, fazenda Sthur, 7.VIII.2002 (fr.), L. Kollmann 5678 (MBML).

Comentários: Subarbusto que ocorre em locais sombreados, não raro crescendo em solo com acúmulo de serapilheira. De fácil identificação na medida em que se apresenta como planta glabra, exceto por duas linhas de tricomas na base do pecíolo que decorre no caule; além disso, apresentam pequenas espigas eretas com brácteas florais cuculadas.

Piper arboreum Aubl. var. arboreum, Hist. Pl. Guiane 1: 23. 1775.

Figura $2 \mathrm{j}$

Arbusto ou arvoreta, 1-4 m alt., ramos glabros com lenticelas. Folhas alternas, pecíolo 0,3-2,5 cm compr., vaginado, canaliculado formando ala, às vezes séssil; lâmina 14-27,6 x 4,2-10,6 cm, estreito-elíptica, elíptica, estreito-ovada, estreito-oblonga, lanceolada, discolor, cartácea, base assimétrica com um lado diferindo do outro em 0,9-2 cm compr., arredondada à aguda, ápice agudo a acuminado, broquidódroma, com 7-10 pares de nervuras secundárias, dispostos ao longo da lâmina. Espigas opostas às folhas, solitárias, eretas, 5,7-11,3 x 0,8-1,3 cm; pedúnculo $0,4-1 \mathrm{~cm}$ compr., bráctea floral triangular arredondada, peltada, glandulosa acima e fimbriada marginalmente; estames 4, estigmas 3, filiformes, estilete ausente. Fruto ca. $2 \mathrm{~mm}$ compr., oblongo, tetragonal, ápice truncado.

Material examinado: Brasil, ES, Itarana, Limoeiro de Santo Antônio, 20.IV.2009 (fl.fr.), V.B. Sarnaglia Junior 47 (VIES); 23.VII.2009 (fl.), V.B. Sarnaglia Junior 57 (VIES); 05.IX.2009 (fr.), V.B. Sarnaglia Junior 158 (VIES); 09.VIII.2010 (fl.fr.), V.B. Sarnaglia Junior 358 (VIES).
Comentários: Arbusto crescendo em locais próximos a corpos dágua em áreas sombreadas ou abertas. Caracteriza-se por ser de fácil reconhecimento no campo, uma vez que se trata de planta glabra cujas folhas apresentam a base da lâmina foliar assimétrica, fortemente desigual, com um lado diferindo do outro em $0,9-2 \mathrm{~cm}$ e por ter as espigas eretas.

\section{Piper caldense C. DC. Linnaea 37: $343 \llbracket 344.1872$.}

Figura 2 k-1

Arbusto 1-3 m alt., ramos glabros. Folhas alternas, pecíolo 0,5-1,5 cm compr., vaginado na base; lâmina 11-19,5 x 3,5-7,9 cm, elíptica, estreito-elíptica, oblonga, estreito-oblonga, levemente discolor, cartácea, glabra, castanho-glandulosa, base assimétrica com um lado diferindo do outro em 2-3 mm compr., aguda a cuneada, ápice acuminado a cuspidado, eucamptódroma, com 5-8 pares de nervuras secundárias, dispostos ao longo da lâmina, com nervuras curtas intermediárias. Espigas opostas às folhas, solitárias, pendentes, apiculadas, 1,94,1 x 0,3-0,6 cm, pedúnculo 0,8-1,5 cm compr.; bráctea floral triangular, papilosa acima e densamente fimbriada marginalmente; estames 4, estigmas 3, filiformes, estilete curto. Fruto ca. $3 \mathrm{~mm}$ compr., oblongo, tri-tetragonal, ápice arredondado.

Material examinado: Brasil, ES, Itarana, Limoeiro de Santo Antônio, 20.IV.2009 (fl.fr.), V.B. Sarnaglia Junior 53 (VIES); 05.IX.2009 (fr.), V.B. Sarnaglia Junior 159 (VIES); 09.VIII.2010 (fr.), V.B. Sarnaglia Junior 355 (VIES); 09.VIII.2010 (fl.), V.B. Sarnaglia Junior 357 (VIES).

Comentários: Este arbusto, desenvolve-se preferencialmente em locais úmidos e sombreados. Trata-se de arbusto glabro com folhas brilhantes de base quase simétricas, profusamente castanho-glandulosas; e curtas espigas pendentes, alvo-cremes quando em flor e esverdeadas quando em fruto.

Piper crassinervium Kunth, Nov. Gen. Sp. 1: 48. 1815 [1816].

Figura 2 m-n

Arbusto 1-3 m alt., ramos glabros. Folhas alternas, pecíolo 1,3-2 cm compr., vaginado na base, canaliculado; 
lâmina 12,5-21,5 x 4,7-10,5 cm, elíptica, estreito-ovada, concolor, glabra, cartácea, base assimétrica com um lado diferindo do outro em 1-3 mm compr., aguda a arredondada, ápice acuminado, eucamptódroma, com 4-5 pares de nervuras secundárias, dispostas até a porção mediana da lâmina. Espigas opostas às folhas, solitárias, eretas, apiculadas, 6-7,8 x 0,3-0,6 cm; pedúnculo 2-8 $\mathrm{mm}$ compr., glabro ou puberulento; bráctea floral triangular a triangular-arredondada, peltada, glabra acima e fimbriada marginalmente; estames 4 , estigmas 3, curvados, estilete 0,5 mm compr. Fruto 2-3 mm, obovoide, ápice arredondado.

Material examinado: Brasil, ES, Itarana, Limoeiro de Santo Antônio, 07.IX.2010 (fl.fr.), V.B. Sarnaglia Junior 360 (VIES).

Material adicional: Brasil, ES, Domingos Martins, estrada para Estação Domingos Martins, 10.VII.1984 (fl.fr.), O. J. Pereira 5373 (VIES).

Comentários: Ocorre próximo a córregos ou estradas, heliófilo ou ciófilo; trata-se de arbusto glabro, com nervação pinada eucamptódroma e nervuras secundárias não ultrapassando a porção mediana da lâmina; de fácil reconhecimento no campo à medida que apresenta suas folhas características e as espigas eretas, contendo flores com o ovário provido de estilete longo e estigmas filiformes curvos.

\section{Piper mollicomum Kunth, Linnaea 13: 648. 1839 [1840].}

Figura 2 i

Arbusto $2 \mathrm{~m}$ alt., ramos vilosos. Folhas alternas, pecíolo 0,5-1 cm compr., vaginado na base, viloso; lâmina 10-18,5 x 3,9-7,3 cm, elíptica, estreito-ovada, lanceolada, discolor, membranácea, vilosa, sedosa ao tato, com tricomas prateados na face abaxial, base assimétrica com um lado diferindo do outro em 2-4 mm compr., obtusa, arredondada ou levemente cordada, ápice acuminado, eucamptódroma, com 5-6 pares de nervuras secundárias, dispostos pouco acima da porção mediana da lâmina. Espigas opostas às folhas, solitárias, levemente curvadas, $8,2-12 \times 0,2-0,3 \mathrm{~cm}$; pedúnculo 0,8-1,9 cm compr., viloso; bráctea floral triangular, peltada, glandulosa acima e densamente fimbriada marginalmente; estames 4, estigmas 3, filiformes, estilete ausente. Fruto ca. $1 \mathrm{~mm}$ compr., puberulento, glanduloso, obovoide, ápice truncado.

Material examinado: Brasil, ES, Itarana, Limoeiro de Santo Antônio, 20.IV.2009 (fr.), V.B. Sarnaglia Junior 55 (VIES).

Material adicional: Brasil, ES, Itaguaçu, Areia Branca, 26.II.2006 (fl.), R. C. Britto et al. 11 (MBML).

Comentários: Arbusto viloso, com nervuras secundárias não ultrapassando o terço superior da lâmina, folhas sedosas ao tato na face abaxial que apresenta tricomas prateados. Espécie que habita locais ensolarados ou sombreados, em áreas de solos úmidos.

\section{Piper tuberculatum Jacq. Icon. Pl. Rar. 2 (16): 2, t. 211. 1795.}

Figura 2 o-p

Arbusto 1,5-3 m alt., ramos puberulentos, com nós providos de tubérculos. Folhas alternas, pecíolo 1-2 cm compr., canaliculado, vaginado, puberulento; lâmina 5,5-11,8 x 2,5-5,9 cm, oblonga, elíptica, largoelíptica, concolor, cartácea, glabra na face abaxial, puberulenta na adaxial, principalmente nas nervuras, base assimétrica com um lado diferindo do outro em 0,4-1 cm compr., arredondada a levemente cordada, ápice agudo, broquidódroma, 8-10 pares de nervuras secundárias, dispostos ao longo da lâmina, com até 3 nervuras a mais num lado em relação a outro. Espigas opostas às folhas, solitárias eretas, 5,3-7,5 x 0,1-0,2 cm; pedúnculo 1,4-2 cm compr., puberulento; bráctea floral triangular peltada, glabra acima e fimbriada lateralmente; estames 4, estigmas 3, filiformes, estilete ausente. Fruto ca. $2 \mathrm{~mm}$, glabro, tetragonal, achatado lateralmente, ápice truncado.

Material examinado: Brasil, ES, Itarana, Limoeiro de Santo Antônio, 01.IX.2012 (fl.fr.), V.B. Sarnaglia Junior 465 (RB).

Comentários: Arbusto heliófilo, puberulento e que apresenta tubérculos no caule; é morfologicamente semelhante a $P$. arboreum do qual difere pela pilosidade, lâminas com menor comprimento, pedúnculos maiores e presença de tubérculos especialmente nos nós caulinares. 


\section{Piper umbellatum L., Sp. Pl. 30.1753.}

Figura 2 q

Arbusto 1-3 m alt., ramos puberulentos a pubescentes, castanho-glanduloso, com lenticelas. Folhas alternas, pecíolo 16-20 cm compr., vaginado na base, canaliculado formando uma ala até metade do pecíolo, puberulento, castanho-glanduloso; lâmina 24-27,5 x 24-28,5 cm, suborbicular, orbicular, concolor, membranácea, densamente castanho-glanduloso, pubescente (principalmente nas nervuras), base cordada, aberta com 5-7 cm de profundidade, ápice curto acuminado, campilódroma, com 12-14 nervuras principais. Espigas axilares, reunidas em umbela de 4-6 espigas, eretas, 6-9,2 x 0,1-0,3 cm; pedúnculo da umbela com 1,2 -1,7 cm compr., pedúnculo da espiga com 2-7 mm compr., puberulento; bráctea floral triangular, peltada, papilosa acima e fimbriada lateralmente; estames 2, estigmas 3, filiforme, estilete ausente. Fruto ca. $1 \mathrm{~mm}$ compr., glabro, glanduloso, oblongo, trigonal, ápice truncado,

Material examinado: Brasil, ES, Itarana, Limoeiro de Santo Antônio, 20.I.2010 (fl.), V.B. Sarnaglia Junior 187 (VIES); 09.VIII.2010 (fl.fr.), V.B. Sarnaglia Junior 356 (VIES).

Comentários: Arbusto heliófilo ou ciófilo, facilmente reconhecido pelas folhas com $24-27,5 \mathrm{~cm}$ de comprimento e 24-28,5 cm de largura, suborbiculares ou orbiculares com nervação campilódroma e inflorescências axilares reunidas em umbelas de espigas.

\section{Agradecimentos}

Os autores agradecem a Coordenação de Aperfeiçoamento de Pessoal de Nível Superior (CAPES) pela bolsa de mestrado concedida ao primeiro autor, e ao Conselho Nacional de Desenvolvimento Científico e Tecnológico ( $\mathrm{CNPq}$ ) pela bolsa de produtividade concedida à última autora. Agradecem aos herbários MBML, RB e VIES pela consulta as suas coleções.

\section{Referências}

CAMPOS, P. B. C.; GAMA, J. J. T.; PEREIRA, L. P.; COSTALOTUFO, L. V.; MORAES, M. O.; GUIMARÃES, E. F.; KATO,
M. J.; FURLAN, M. Antitumor activity of extracts from Peperomia elongata. Pharmaceutical Biology, Lisse, v. 45, n. 10, p. 760-765, 2007.

CARVAlHO-SILVA, M. Peperomia Ruiz \& Pav. no Brasil: morfologia e taxonomia do subgênero Rhynchophorum (Miq.) Dahlst. 2008. 156 f. Tese (Doutorado em Botânica) - Instituto de Pesquisas Jardim Botânico do Rio de Janeiro, Rio de Janeiro. 2008. FELIPPE, L. G.; BALDOQUI, D. C.; BOLZANI, V. S.; KATO, M. J.; GUIMARÃES, E. F.; AMBROSIO, D. L.; CICARELLI, R. M. B.; FURLAN, M. Trypanocidal tetrahydrofuran lignans from Peperomia blanda. Phytochemistry, New York, v. 69, n. 2, p. 445450, 2008.

FIDALGO, O.; BONONI, V. L. R. Técnicas de coleta, preservação e herborização de material botânico. 2. ed. São Paulo: Instituto de Botânica, 1989. 61 p.

FLEMING, T. H. Dispersal ecology of Neotropical Piper shrubs and treelets. In: DYER, A.; PALMER, A. D. N. (Ed.). Piper: a model genus for studies of phytochemistry, ecology, and evolution. New York: Kluwer Academic, 2004. p. 58-77.

FRODIN, D. G. History and concepts of big plant genera. Taxon, Utrecht, v. 53, n. 3, p. 753-776, 2004.

GUIMARÃES, E. F.; CARVALHO-SILVA, M.; MONTEIRO, D.; MEDEIROS, E. S. Piperaceae. 2012. Disponível em: $<$ http:// floradobrasil.jbrj.gov.br/2012/FB000190>. Acesso em: 1 fev. 2013.

HICKEY, L. J. Classification of the architecture of dicotyledonous leaves. American Journal of Botany, Columbus, v. 6, n. 1, p. 17 33, 1973

HICKEY, M.; KING, C. The Cambridge illustrated glossary of botanical terms. Cambridge: Cambridge University Press, 2003. $210 \mathrm{p}$.

IBGE - INSTITUTO BRASILEIRO DE GEOGRAFIA E ESTATÍSTICA. Manual técnico da vegetação brasileira. Rio de Janeiro: IBGE, 2012. 275 p.

INCAPER - INSTITUTO CAPIXABA DE PESQUISA, ASSISTÊNCIA TÉCNICA E EXTENSÃO RURAL. Caracterização climática do município de Itarana. 1999. Disponível em: <http:/hidrometeorologia.incaper.es.gov.br/ caracterizacao/itarana_carac.php $>$. Acesso em: 10 jan. 2013.

JARAMILLO, M. A.; MANOS, P. S.; ZIMMER, E. A. Phylogenetic relationships of the perianthless Piperales: reconstructing the evolution of floral development. International Journal of Plant Sciences, Chicago, v. 165, n. 3, p. 403-416, 2004.

SILVA, J. K. R.; ANDRADE, E. H. A.; GUIMARÃES, E. F.; MAIA, J. G. S. Essential oil composition, antioxidant capacity and antifungal activity of Piper divaricatum. Natural Product Communications, Westerville, v. 5, n. 3, p. 477-480, 2010.

SILVA, J. K. R.; ANDRADE, E. H. A.; KATO, M. J.; CARREIRA, L. M. M.; GUIMARÃES, E. F.; MAIA, J. G. S. Antioxidant capacity and larvicidal and antifungal activities of essential oils and extracts from Piper krukoffii Yuncker. Natural Product Communications, Westerville, v. 6, p. 1-6, 2011.

TEBBS, M. C. Revision of Piper (Piperaceae) in the New World 1. Review of characters and taxonomy of Piper section Macrostachys. Bulletin of the British Museum (Natural History) Botany, London, v. 19, p. 117-158, 1989

WANKE, S.; SAMAIN, M. S.; VANDERSCHAEVE, L.; 
MATHIEU, G.; GOETGHEBEUR, P.; NEINHUIS, C. Phylogeny of the genus Peperomia (Piperaceae) inferred from the trnk/matk region (cpDNA). Plant Biology, Stuttgart, v. 8, n. 1, p. 93-102, 2006.

YUNCKER, T. G. New species of Piperaceae from Brazil. Boletim do Instituto de Botânica, São Paulo, v. 3, p. 140-195, 1966.

YUNCKER, T. G. The Piperaceae of Brazil I: Piper $\square$ Group I, II, III, IV. Hoehnea, São Paulo, v. 2, p. 19-366, 1972.

YUNCKER, T. G. The Piperaceae of Brazil. II: Piper - Group V; Ottonia; Pothomorphe; Sarcorhachis. Hoehnea, São Paulo, v. 3, p. 29-284, 1973.

YUNCKER, T. G. The Piperaceae of Brazil. III: Peperomia; Taxa of uncertain status. Hoehnea, São Paulo, v. 4, p. 71-413, 1974. 